\title{
Forecasting Peak Wind Gusts Using Meteorologically Stratified Gust Factors and MOS Guidance $\mathscr{O}$
}

\author{
JONATHAN D. W. KAHL \\ Atmospheric Science Group, Department of Mathematical Sciences, University of Wisconsin-Milwaukee, \\ Milwaukee, Wisconsin
}

(Manuscript received 16 March 2020, in final form 16 April 2020)

\begin{abstract}
Gust prediction is an important element of weather forecasting services, yet reliable methods remain elusive. Peak wind gusts estimated by the meteorologically stratified gust factor (MSGF) model were evaluated at 15 locations across the United States during 2010-17. This model couples gust factors, site-specific climatological measures of "gustiness," with wind speed and direction forecast guidance. The model was assessed using two forms of model output statistics (MOS) guidance at forecast projections ranging from 1 to $72 \mathrm{~h}$. At 11 of 15 sites the MSGF model showed skill (improvement over climatology) in predicting peak gusts out to projections of $72 \mathrm{~h}$. This has important implications for operational wind forecasting because the method can be utilized at any location for which the meteorologically stratified gust factors have been determined. During particularly windy conditions the MSGF model exhibited skill in predicting peak gusts at forecast projections ranging from 6 to $72 \mathrm{~h}$ at roughly half of the sites analyzed. Site characteristics and local wind climatologies were shown to exert impacts on gust factor model performance. The MSGF method represents a viable option for the operational prediction of peak wind gusts, although model performance will be sensitive to the quality of the necessary wind speed and direction forecasts.
\end{abstract}

\section{Introduction}

Wind gusts, short-lived extremes within the spectrum of wind variation, occur when high momentum air is brought to the surface. They accompany both convective and nonconvective phenomena, and are sensitive to various physical factors including wind speed, boundary layer turbulence, surface roughness, stability, and topographic flows (Letson et al. 2018; Harris and Kahl 2017). Wind gusts are often associated with serious hazards and structural damage (Sheridan 2018) and thus are an important consideration for a wide range of applications, activities and research areas. Principal among these are structural design for wind loads and watertightness (Van Den Bossche et al. 2013), wind energy generation (Sinden 2007), insurance, timber, and aviation industries (Klawa and Ulbrich 2003; Usbeck et al. 2009; Manasseh and Middleton 1999), and fire danger

\footnotetext{
Supplemental information related to this paper is available at the Journals Online website: https://doi.org/10.1175/WAF-D-200045.s1.
}

Corresponding author: Jonathan D. W. Kahl, kahl@uwm.edu
(Adame et al. 2018). Gusts associated with nonconvective high winds are of special concern-they have the potential to cause more injuries and fatalities than thunderstorm or hurricane winds, especially since people are less likely to take shelter in a nonconvective high wind scenario as compared to a tornadic situation (Ashley and Black 2008).

Reliable gust forecasts can reduce the risk of human danger, cost drawbacks, and structural damage. For wind energy, reliable forecasts can prevent cut-out events in which wind turbines abruptly stop, causing fatigue in turbine components, transitory changes in power transmission, and losses in energy yield (Gutiérrez and Fovell 2018; Suomi and Vihma 2018; Jung et al. 2017).

Gust prediction is an important element of weather forecasting services. Despite its importance, however, reliable gust prediction remains elusive. This is primarily because (i) energy-containing turbulent eddies in which gusts are imbedded are usually far too small for observing networks and mesoscale numerical models to resolve, creating the need for parameterizations and downscaling of model output (Fovell and Cao 2014); and (ii) observational wind data contain reporting artifacts that hinder the development and verification of gust 
forecast models (Harris and Kahl 2017). Current gust forecasting techniques include physical approaches involving features of boundary layer turbulence, and statistical models employing extreme value statistics or underlying assumptions about wind distribution as a function of predictor variables (Sheridan 2011, 2018).

One statistical approach, the gust factor model, employs a combination of climatological measures of local gustiness along with wind speed forecasts. With this model, peak wind gusts are predicted by multiplying the gust factor, the ratio of the peak wind gust to the average wind speed, by a predicted wind speed. The gust factor is based on observed wind and gusts and thus is a climatological measure of gustiness. Harris and Kahl (2017), hereafter HK17, showed that the gust factor model is a viable method of forecasting wind gusts when the gust factors are stratified by wind speed and wind direction. HK17 demonstrated the potential of the meteorologically stratified gust factor (MSGF) model by utilizing a "perfect prog" evaluation procedure in which wind forecast errors were ignored. Their evaluation can be made more practical by considering actual wind speed forecasts, a crucial component of any gust forecasting technique (Fovell and Cao 2014).

In this paper we extend the work of HK17 by evaluating the MSGF model when coupled with wind forecasts provided by two model output statistics (MOS) products. The evaluation is performed over 2010-17 at 15 diverse locations across the United States. Specifically, we address the following research questions. Does the MSGF model demonstrate skill in predicting peak gusts when coupled with MOS wind forecasts? How is model performance affected by MOS type, forecast projection, and during strong wind events? Our analysis offers evidence that the MSGF model represents a viable option for the operational prediction of peak wind gusts.

\section{Data and methods}

\section{a. Wind and gust data}

Wind and gust measurements over the period 2010-17 from the U.S. Automated Surface Observing System (ASOS) were obtained for 15 stations from online archives provided by the National Centers for Environmental Information (dataset 6405, available at ftp.ncdc.noaa.gov/ $\mathrm{pub} / \mathrm{data} / \mathrm{asos}-\mathrm{onemin})$. Stations were selected at diverse locations across the United States to represent different wind climatologies, altitudes, climate types, and surface characteristics. Wind data with 1-min resolution, roughly 4000000 observations at each station
(Fig. 1; Table 1), were utilized in the present study to avoid the averaging and reporting artifacts present in the considerably less voluminous hourly dataset (HK17).

Winds at the ASOS stations are measured by Vaisala, Inc. model 425 sonic anemometers at an altitude of $10 \mathrm{~m}$ AGL (www.weather.gov/asos). Wind speed and direction reported in the ASOS database represent 2-min averages of 3-s averages, reported every minute, while the gust represents the maximum 3-s average occurring each minute. Wind speed and gust are reported in integer values of knots $\left(\mathrm{kt} ; 1 \mathrm{kt}=0.514 \mathrm{~m} \mathrm{~s}^{-1}\right)$ and rounded up to the nearest knot (Letson et al. 2018).

Since the raw 1-min wind and gust records did not undergo extensive quality control measures (EPA 2015), several additional quality checks were performed to ensure the fidelity of the observational dataset. First, all data files were first filtered for records that were repeated, out of chronological order, or "garbled". Second, gross error checks were performed to exclude records with missing data fields, negative wind speeds, or wind directions outside of $0^{\circ}-360^{\circ}$. Finally, the quality control measures of Letson et al. (2018) were applied to eliminate erroneously large winds and gusts. The resulting 1-min data were used to construct an hourly dataset containing mean wind speed, mean wind direction, peak wind gust, and gust factor (GF $=$ peak gust $/$ mean wind speed). A minimum of 54 (total) 1-min measurements were required to produce an hourly record. This process yielded between 60000 and 67000 hourly records at all but one site, representing $86 \%-96 \%$ of all possible reporting hours (Table 1). The exception was Lander, Wyoming, with 58536 hourly records $(83.5 \%$ of possible reporting hours).

\section{b. Meteorologically stratified gust factors}

Average hourly gust factors for each site were stratified by both wind speed $(0-5,5-10,10-15$, and $>15 \mathrm{kt})$ and wind direction $\left(30^{\circ}\right.$ bins $)$. In the present work, "meteorologically stratified" refers to this stratification, which was shown by HK17 to give the best performance in gust factor models. An example in the form of a "gust web" diagram (Fig. 2) illustrates features of the wind and gust climatology of the Providence, Rhode Island, site (KPVD). Gust factors at KPVD exhibit the typical decrease with increasing wind speed (e.g., Letson et al. 2018). At this site, stronger winds (mean speeds $>10 \mathrm{kt}$ ) occur most frequently with wind directions in a broad sector from south-southeast $\left(150^{\circ}\right)$ clockwise to north-northeast $\left(30^{\circ}\right)$. Gust factors associated with winds $>15 \mathrm{kt}$ are largest in the northwest sector $(\mathrm{GF}=1.81)$ and smallest in the north-northeast sector $(\mathrm{GF}=1.58)$, with differences likely due to horizontal inhomogeneity in surface roughness (Pryor et al. 2014; 


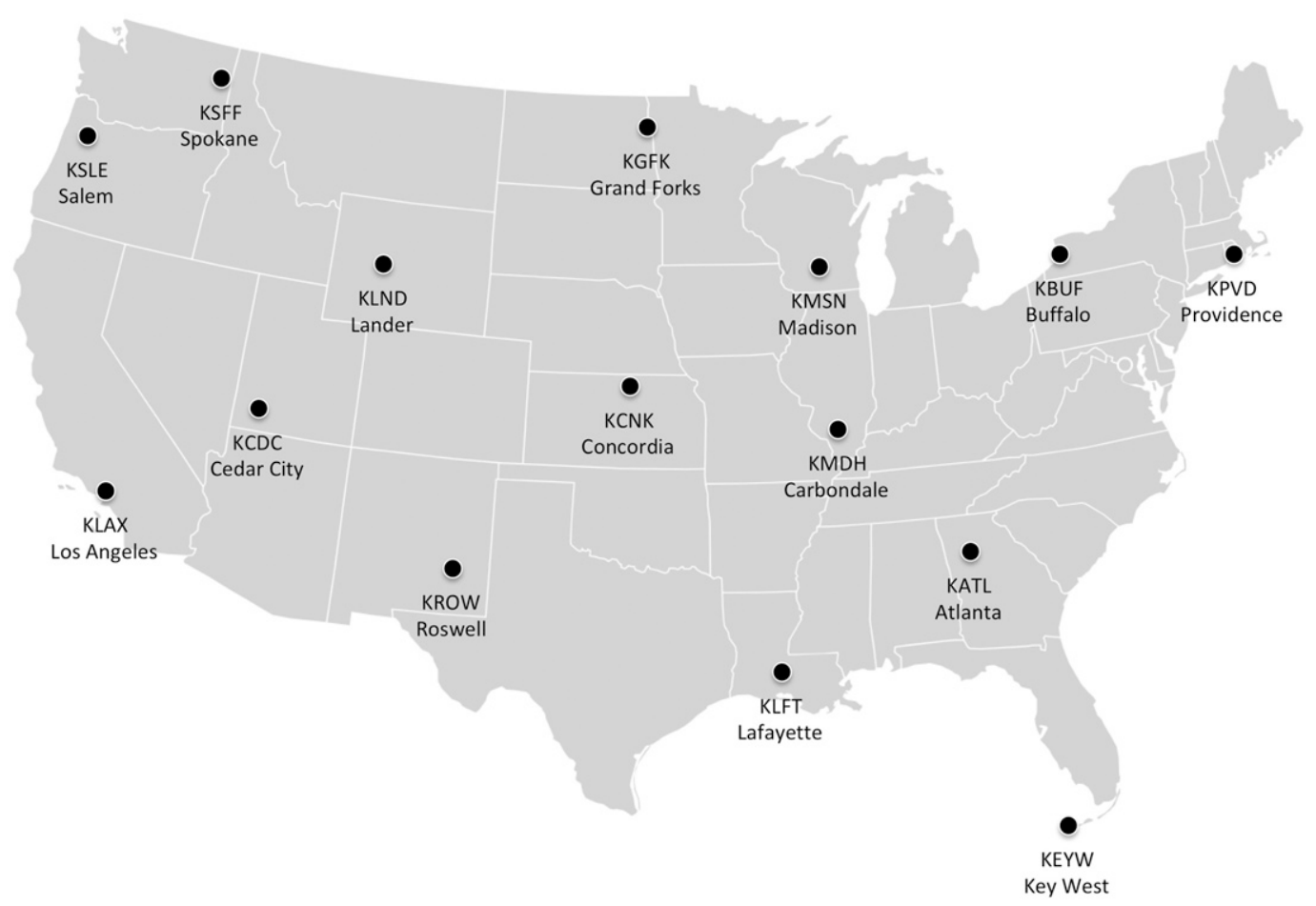

FIG. 1. Locations of ASOS sites at which the meteorologically stratified gust factor model was evaluated.

Suomi et al. 2013). Meteorologically stratified gust factors for the other sites are provided in the online supplemental material.

\section{c. MOS forecasts}

Application of the gust factor model to predict peak gusts requires wind forecasts. In this study, wind speed and direction forecasts were obtained from MOS guidance (Glahn and Lowry 1972), a widely used product with a demonstrated improvement upon raw forecast model output (e.g., Ma et al. 2018). The short-range GFS MOS and NAM MOS products were utilized (https://www.nws.noaa.gov/mdl/synop/ products.php), with data files accessed from the Iowa

TABLE 1. Site characteristics and database details.

\begin{tabular}{|c|c|c|c|c|c|c|}
\hline Site & ID & $\begin{array}{l}\text { Latitude } \\
\qquad\left({ }^{\circ} \mathrm{N}\right)\end{array}$ & $\begin{array}{l}\text { Longitude } \\
\qquad\left({ }^{\circ} \mathrm{W}\right)\end{array}$ & $\begin{array}{l}\text { Altitude } \\
\text { (m MSL) }\end{array}$ & $\begin{array}{l}\text { No. of hourly mean wind and } \\
\text { peak gust records }\end{array}$ & $\begin{array}{l}\text { Percent possible } \\
\text { reporting hours }\end{array}$ \\
\hline Grand Forks, North Dakota & KGFK & 47.94 & 97.18 & 257 & 64981 & 92.7 \\
\hline Spokane, Washington & KSFF & 47.68 & 117.32 & 596 & 66096 & 94.3 \\
\hline Salem, Oregon & KSLE & 44.91 & 123.00 & 62 & 66061 & 94.2 \\
\hline Madison, Wisconsin & KMSN & 43.14 & 89.35 & 264 & 64695 & 92.3 \\
\hline Buffalo, New York & KBUF & 42.94 & 78.74 & 218 & 67341 & 96.0 \\
\hline Lander, Wyoming & KLND & 42.82 & 108.73 & 1704 & $58536^{\mathrm{a}}$ & 83.5 \\
\hline Providence, Rhode Island & KPVD & 41.72 & 71.43 & 17 & $60467^{b}$ & 86.2 \\
\hline Concordia, Kansas & KCNK & 39.55 & 97.65 & 448 & $60911^{\mathrm{a}}$ & 86.9 \\
\hline Carbondale, Illinois & $\mathrm{KMDH}$ & 37.78 & 89.25 & 124 & 66424 & 94.7 \\
\hline Cedar City, Utah & $\mathrm{KCDC}$ & 37.71 & 113.09 & 1703 & 63066 & 89.9 \\
\hline Los Angeles, California & KLAX & 33.94 & 118.39 & 30 & 64904 & 92.6 \\
\hline Atlanta, Georgia & KATL & 33.63 & 84.44 & 308 & 65299 & 93.1 \\
\hline Roswell, New Mexico & KROW & 33.31 & 104.51 & 1112 & 65055 & 92.8 \\
\hline Lafayette, Louisiana & KLFT & 30.21 & 91.99 & 12 & 63233 & 90.2 \\
\hline Key West, Florida & KEYW & 24.56 & 81.75 & 1 & 65570 & 93.5 \\
\hline
\end{tabular}

a The 1-min ASOS data were unavailable from June to December 2013.

${ }^{\mathrm{b}}$ The 1-min ASOS data were unavailable from June to December 2017. 


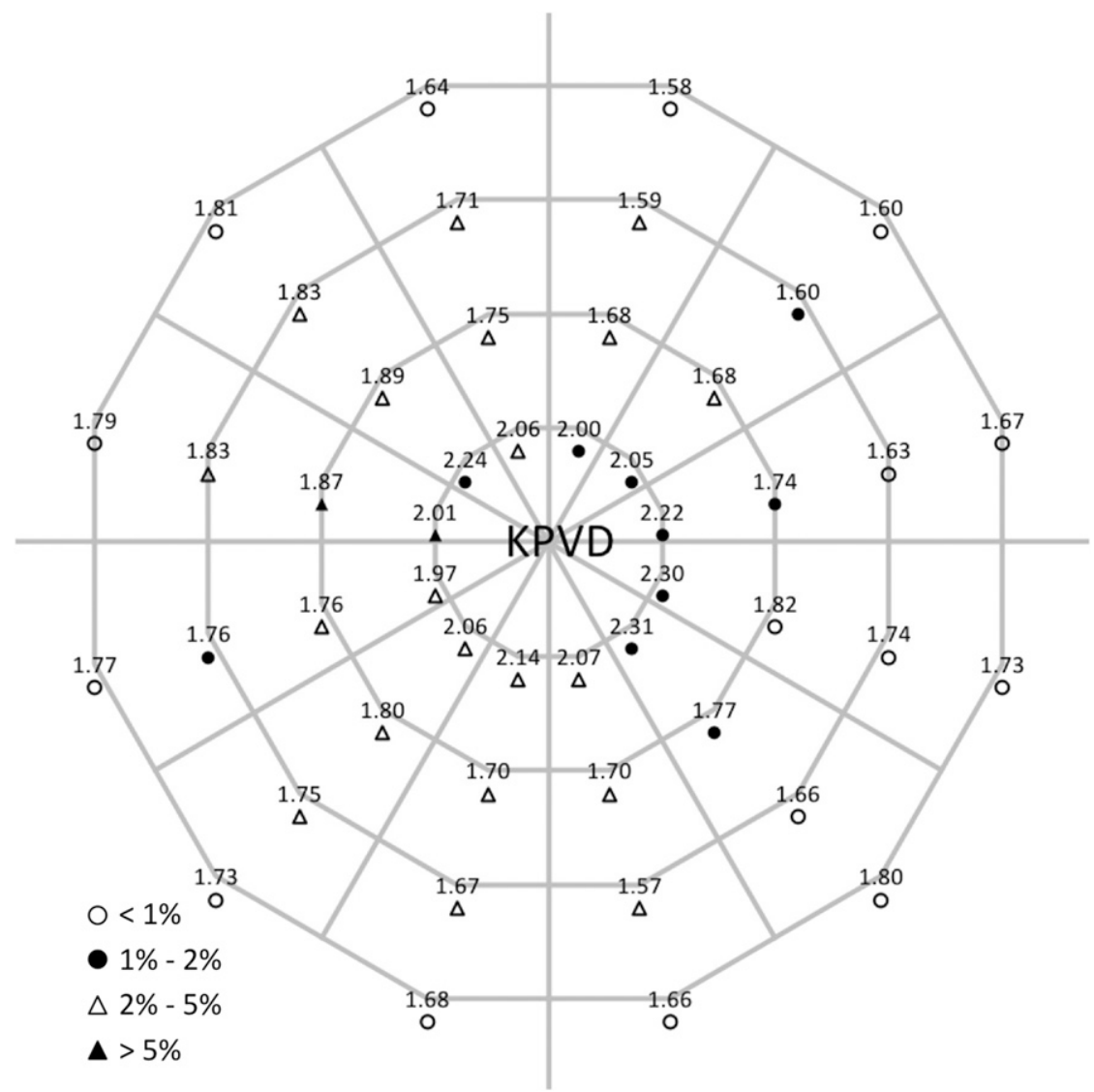

FIG. 2. Gust web showing meteorologically stratified gust factors at KPVD based on 60467 hourly wind speeds, wind directions, and peak gusts during 2010-17. The concentric rings represent mean wind speed ranges: $0-5$ (center), 5-10, 10-15, and $>15 \mathrm{kt}$ (outermost). The radial lines represent the boundaries of $30^{\circ}$ wind sectors, clockwise from north as per meteorological convention. The symbols represent the occurrence frequencies of mean wind speed and direction combinations.

State University server (https://mesonet.agron.iastate. edu/mos/).

The GFS (NAM) MOS is initialized every $6 \mathrm{~h}(12 \mathrm{~h})$ and provides forecasts at projections of $6-60 \mathrm{~h}$ at $3 \mathrm{~h}$ intervals, and at 66 and $72 \mathrm{~h}$. At any given verification hour, therefore, both MOS products provide wind speed and direction forecasts at multiple projections. The daily pattern of MOS data availability is illustrated in Fig. 3. At 0300 UTC on any given day, for example, the NAM MOS provides wind forecasts at projections of $15,27,39$, and $51 \mathrm{~h}$, while the GFS MOS provides forecasts at projections of $9,15,21,27,33,39$, 45,51 , and $57 \mathrm{~h}$. Over the $2010-17$ period, a total of approximately 245000 GFS MOS and 122500 NAM MOS forecasts were analyzed at each site included in this study.

MOS guidance is a postprocessing product provided by many numerical weather modeling systems (e.g., Struzewska et al. 2016). There is a growing selection of different MOS products, including those for ensembles (Thorarinsdottir and Gneiting 2010; Veenhuis 2013) and those employing adaptive techniques that sequentially update the forecasts as new observations become available (Pelosi et al. 2017). Our intention here is not to evaluate specific MOS forecast products, but rather to evaluate the performance of the meteorologically stratified gust factor model when coupled with commonly used MOS wind forecasts.

\section{d. Application and evaluation of the meteorologically stratified gust factor model}

Application of the gust factor model involves solving the equation

$$
\text { gust }_{\text {fcst }}=\mathrm{GF} \times \text { wspd }_{\text {fcst }} \text {, }
$$

where gust $t_{\text {fcst }}$ is the peak gust being forecast for a particular hour, $\operatorname{wspd}_{\mathrm{fcst}}$ is the wind speed forecast valid 


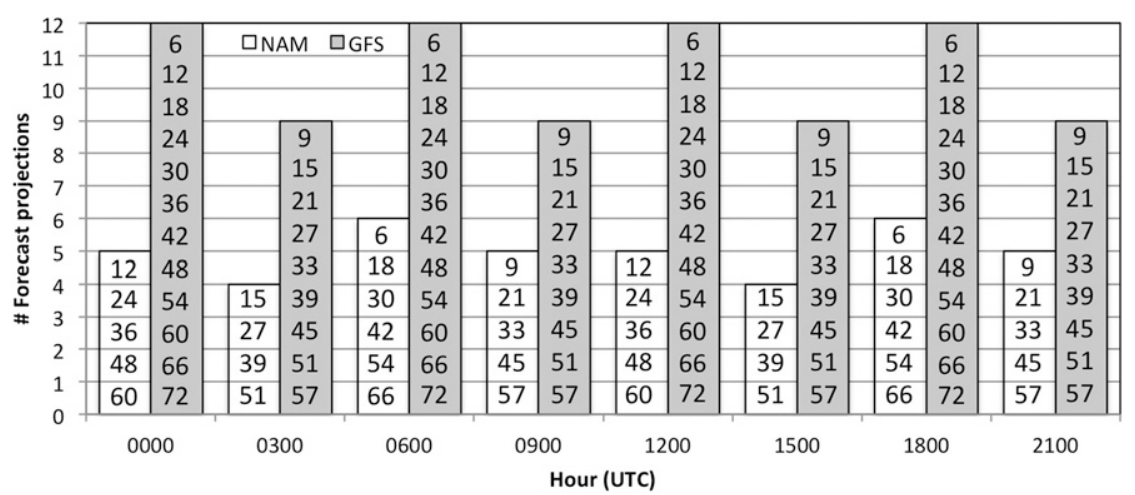

FIG. 3. NAM MOS and GFS MOS forecast projections available at different hours of the day. Numbers within bars show forecast projections (h) valid at each verification time.

for that hour, ${ }^{1}$ and GF is the gust factor that depends on $\mathrm{wspd}_{\mathrm{fcst}}$ and the wind direction forecast. Using wind speed and direction guidance provided by the GFS MOS and NAM MOS coupled with meteorologically stratified gust factors prepared using 1-min wind observations as described earlier, hourly peak gusts forecasts using (1) were prepared for each site at forecast projections ranging from 6 to $72 \mathrm{~h}^{2}$

Verification metrics of bias $\left(\right.$ gust $_{\mathrm{fcst}}-$ gust $_{\mathrm{obs}}$ ) and absolute error ( $\mid$ bias $\mid$ ) were used to evaluate the performance of the gust factor model. The hourly peak wind gust determined from the 1-min data (gust ${ }_{\mathrm{obs}}$ ) served as verification. Perfect prog (PPROG) model forecasts were evaluated in the same way. For PPROG forecasts, however, $\mathrm{wspd}_{\mathrm{fcst}}$ in Eq. (1) is the observed mean wind speed obtained from the 1-min data. PPROG forecasts also utilize the observed mean wind direction, likewise obtained from the 1-min data, as both wind speed and direction determine the appropriate MSGF (i.e., wind direction- and wind speed-dependent gust factor) to use.

Metrics were also determined for the no-skill models of persistence (PERS, projections 1-6h only) and

\footnotetext{
${ }^{1}$ The wind speed forecasts provided by MOS guidance refer to wind conditions at the top of the hour, whereas $\mathrm{wspd}_{\mathrm{fcst}}$ in Eq. (1) represents the mean wind speed over the entire hour. HK17 showed that this discrepancy has little importance in the application of the gust factor model due to the gap in the wind speed energy spectrum occurring between periods of a few minutes and a few hours.

${ }^{2}$ The Localized Aviation MOS Program (LAMP) is one of the few MOS products that include wind gust guidance (Ghirardelli and Glahn 2010). LAMP gust forecasts, however, predict the strongest wind gust during minutes $43-52$ of the hour previous to the forecast hour (Ghirardelli 2005; HK17), while the MSGF model predicts the peak gust during the entire forecast hour. Due to this difference, comparisons between the two forecasts are not considered here.
}

climatology (CLIM), with gust climatologies prepared using observed peak wind gusts stratified by hour and season (Fig. 4). Peak gust climatologies for the other sites are included in the supplemental material. Model details are provided in Table 2, along with descriptions of database subsets used for verification. Forecast verification was performed using observed peak gusts for all available hours (subsets "ALL"), and for "windy" conditions [i.e., hours with observed mean wind speeds of at least $19 \mathrm{kt}$ (subsets "19")]. Absolute error distributions for selected models were compared with similar distributions for no-skill climatology forecasts via the sign test (Mendenhall et al. 1990), and differences were considered to be statistically significant when the null hypothesis (of no difference) was rejected at the $99 \%$ confidence level. A model was considered to have skill if its absolute error distribution was significantly different than that of climatology, with a smaller mean value.

\section{Results}

\section{a. Peak gust forecast performance at KPVD}

Detailed model evaluation results are shown for one site, KPVD, followed by selected results at the other sites analyzed.

We first discuss mean absolute errors (MAE) as a function of forecast projection (Fig. 5). The perfect prog gust factor methodology (PPROG) displayed a small MAE of $1.3 \mathrm{kt}$, confirming the potential of the MSGF model provided that accurate wind speed and direction forecasts are available (HK17). For the no-skill methods, persistence forecasts (Fig. 5a) perform best at shorter forecast projections (1-2h) while climatology, which provides a benchmark against which the MSGF models are compared, performs best between the 4 and $6 \mathrm{~h}$ projections. It should be noted, however, that unlike climatology forecasts, persistence forecasts of peak gusts 


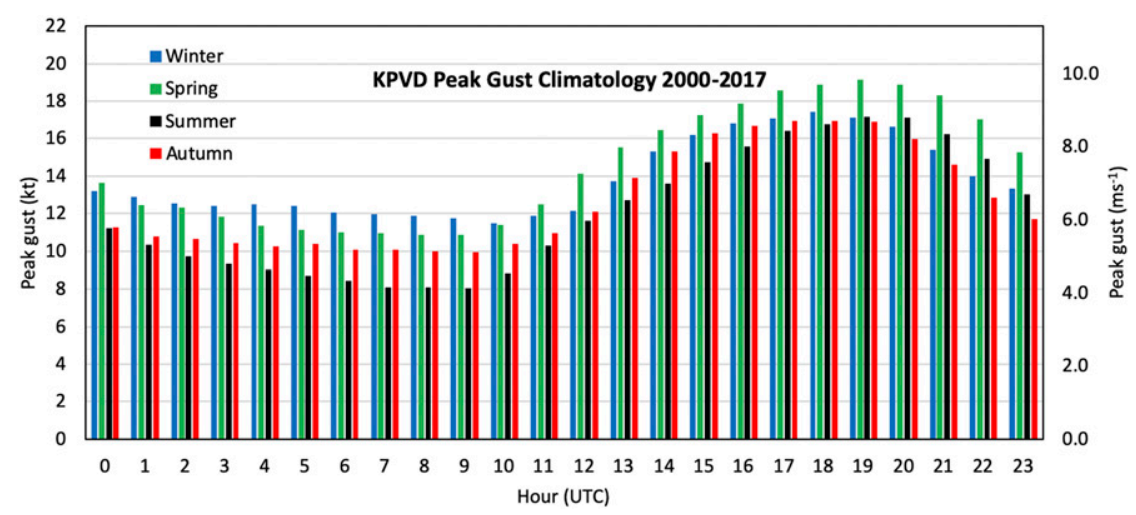

FIG. 4. Peak gust climatology for KPVD, stratified by hour and season.

may not be operationally feasible because they require the archival of gust observations free of the restrictive reporting protocols accompanying the hourly ASOS dataset (HK17).

The GFNAM (Fig. 5b) and GFGFS (Fig. 5c) MSGF models exhibit skill out to forecast projections of $72 \mathrm{~h}$ when all hours are considered (data subsets NAM-ALL and GFS-ALL). The MAEs of both models show a general increase with increasing forecast projection. Errors are larger during windier conditions (data subsets NAM-19 and GFS-19), with the GFGFS model performing better, particularly at projections $>60 \mathrm{~h}$. During these conditions the GFGFS forecasts exhibit skill (perform better than climatology) at projections out to $39 \mathrm{~h}$, while the GFNAM model exhibits skill at projections up to $21 \mathrm{~h}$.

Insight into model behavior may be gained by inspecting forecast sensitivity to observed wind speed and direction. The PPROG (Figs. 6a,b) model exhibits a relatively constant range of bias at all wind speeds and directions indicating that, given an accurate wind forecast, the meteorologically stratified gust factor provides a good description of the local gust climatology. The CLIM model, on the other hand, exhibits strong sensitivity to observed wind speed and direction (Figs. 8c,d). Not surprisingly, CLIM gusts are overpredicted at smaller wind speeds and strongly underpredicted in windy conditions. The small CLIM bias associated with winds from the $60^{\circ}-150^{\circ}$ sector reflects the influence of heterogeneous terrain on turbulence and gust generation. Wind from this sector passes over Narragansett Bay, a smoother upwind surface in comparison with the urban landscape surrounding the KPVD ASOS measurement site.

The GFNAM (Figs. 6e,f) and GFGFS (Figs. 6g,h) models at 24-h forecast projections are relatively insensitive to observed wind speed, although model bias is more often positive (negative) with smaller (larger) wind speeds. Both models exhibit a reduced sensitivity to winds in the $60^{\circ}-150^{\circ}$ sector, similar to CLIM forecasts. This is due to the small frequency of winds from this $90^{\circ}$ sector (7.8\%), particularly stronger winds (Fig. 7). Mean wind speeds larger than $15 \mathrm{kt}$ occurred during only $86 \mathrm{~h}$ (0.14\%) at KPVD during the 2010-17 period.

The performance of the MSGF models may also be assessed using the longest forecast projection (LFP) statistic, indicating the longest forecast projection up to which a particular model shows skill at all projections. At KPVD the value of the LFP statistic was $72 \mathrm{~h}$ for both GFNAM and GFGFS models when all hours were considered (data subsets GFS-ALL and NAM-ALL). During the windiest conditions (data subsets GFS-19 and NAM-19), the GFGFS model was skillful out to $39 \mathrm{~h}$ while the GFNAM model exhibits skill only through projections of $21 \mathrm{~h}$.

\section{b. Summary evaluation of peak gust forecasts at all 15 stations}

The performance of the gust forecast models at all sites analyzed is presented in Table 3 . Starting with the no-skill models, MAEs for the PPROG forecasts were in a modest range of $1.1-1.8 \mathrm{kt}$ at all stations except KLND, once again confirming the robustness and utility of the gust factor model when accurate wind speed and direction forecasts are available (HK17). MAEs for the CLIM forecasts, which provide a benchmark in which forecast skill is assessed, ranged from 4.0 to $5.8 \mathrm{kt}$ at all stations except KLAX. No-skill forecasts at KLND and KLAX exhibited some unusual behavior. At KLND the PPROG MAEs were the largest of all sites analyzed $(2.0 \mathrm{kt})$, while at KLAX the CLIM MAEs were the smallest $(2.5 \mathrm{kt})$. Gust forecast results for KLND and KLAX are discussed in the next section (see Table 1 for site name identifiers).

Peak gust forecast results for 24-h forecast projections are shown in Table 3. The GFNAM and GFGFS models were also evaluated and compared at projections of 
6-, 12-, and 18-h. Except where indicated, the qualitative model performance at these other projections (not shown) was similar to performance at the 24-h projection.

The 24-h projection forecast results for the GFNAM and GFGFS models indicate MAEs less than or equal to those for CLIM forecasts for 13 and 12 sites, respectively, when all hours are considered (data subsets NAM-ALL and GFS-ALL). These results are statistically significant, indicating that these models demonstrate skill. The GFNAM model demonstrated skill at fewer (8-10) sites, however, when forecast projections of 6-, 12-, and 18-h were considered (not shown in Table 3). At 6 sites the GFGFS model similarly produced skillful 24-h projection gust forecasts for the windy GFS-19 data subset, demonstrating the model's utility during the windiest conditions. The GFNAM model demonstrated skillful 24-h peak gust forecasts for the windy NAM-19 subset at only 3 sites, however, at 6-, $12-$, and 18-h projections skillful performance was observed at 4-7 sites (not shown).

The performance of the MSGF models was also assessed using the "longest forecast projection" (LFP) statistic (Table 3). When all hours are considered (data subsets NAM-ALL and GFS-ALL) the LFP statistic for both the GFNAM and GFGFS models is $72 \mathrm{~h}$ at most sites. This indicates that on the average during the 8-yr period analyzed, the gust factor model shows skill when coupled with wind speed and direction forecasts at projections out to $72 \mathrm{~h}$ from both the NAM and GFS MOS products. At most sites, the MSGF models also exhibit skill at sizeable forecast projections when the analysis was restricted to windy or gusty conditions. Considering the windier NAM-19 and GFS-19 data subsets, the GFNAM and GFGFS models each display LFP statistics of $6 \mathrm{~h}$ or more at roughly half of the sites. The GFGFS model performs somewhat better, with LFP of $24 \mathrm{~h}$ or more at 6 sites as compared to 3 sites for the GFNAM model. During these windy conditions the models exhibited less skill (LFP statistics of "none") at KSFF, KSLE, KLND, KMDH, KLAX, KROW, and KLFT. The majority of these sites have nearby heterogeneous terrain. This suggests that the performance of the meteorologically stratified gust factor methodology may be limited at sites with complex surface characteristics, and might benefit from gust factors prepared with more detailed meteorological stratifications (e.g., $15^{\circ}$ wind direction bins instead of $30^{\circ}$ bins).

\section{c. Peak gust forecast performance at KLND and KLAX}

While the gust factor models generally exhibit skill in forecasting peak gusts, often out to projections of $24 \mathrm{~h}$ or 

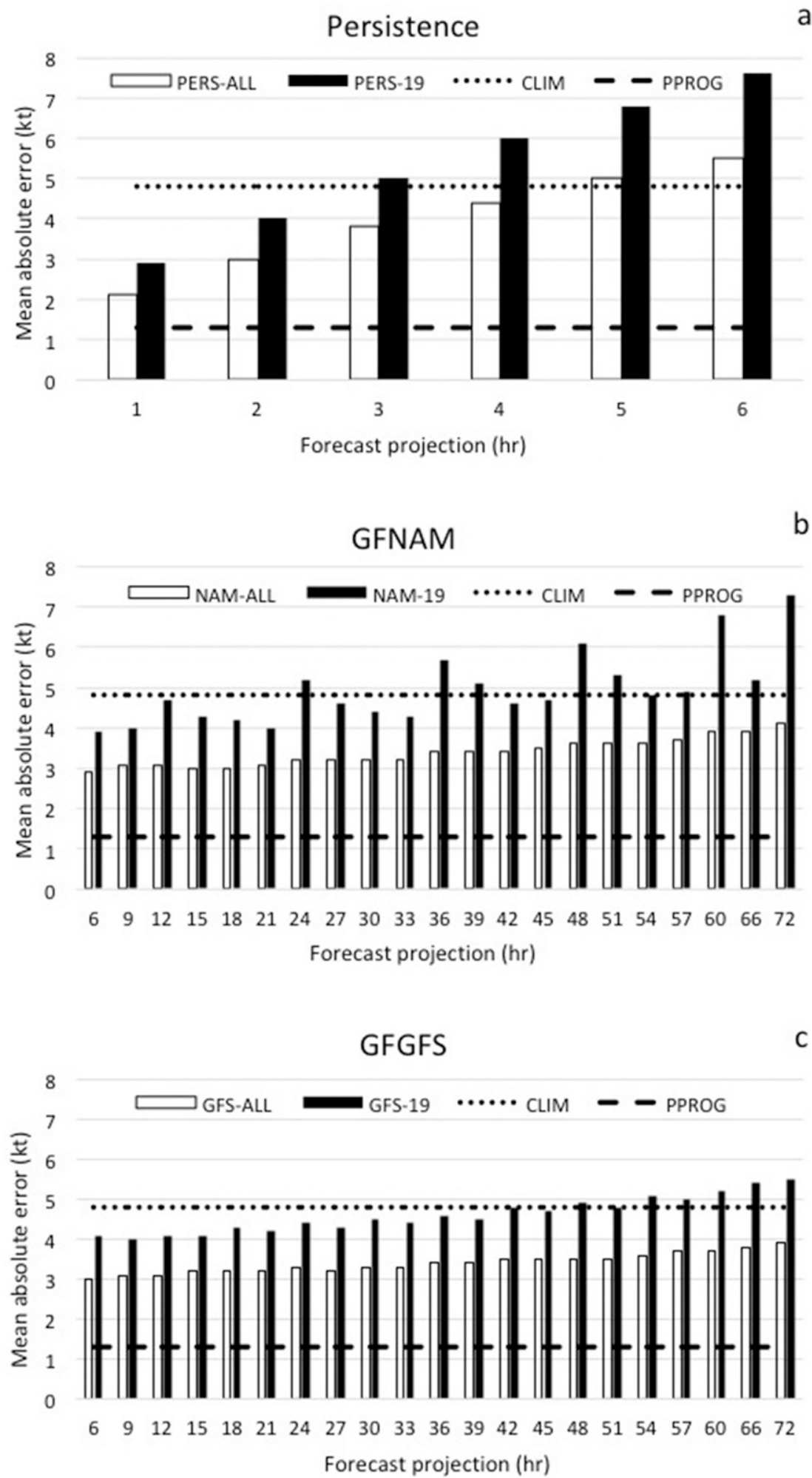

FIG. 5. Mean absolute errors in peak gust forecasts at KPVD. (a) PERS model, (b) GFNAM model, and (c) GFGFS model. Climatology (CLIM) and perfect prog (PPROG) forecast errors are included in all panels. Models and evaluation data subsets are described in Table 2. 

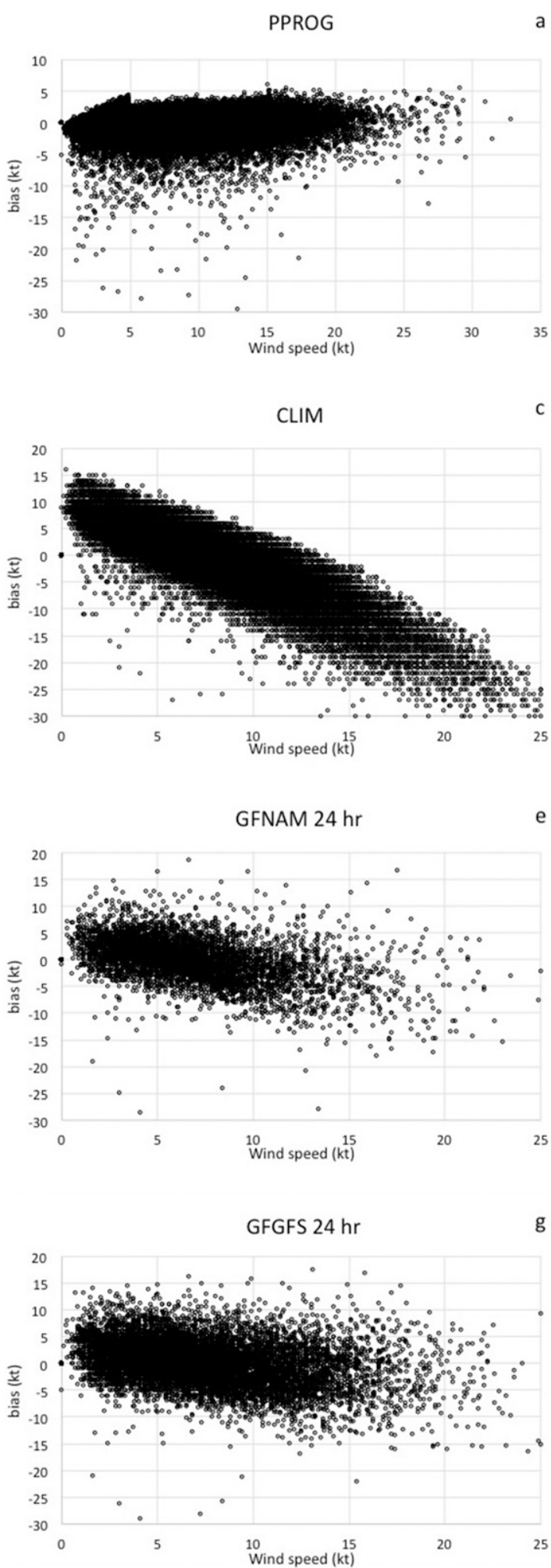

e
PPROG

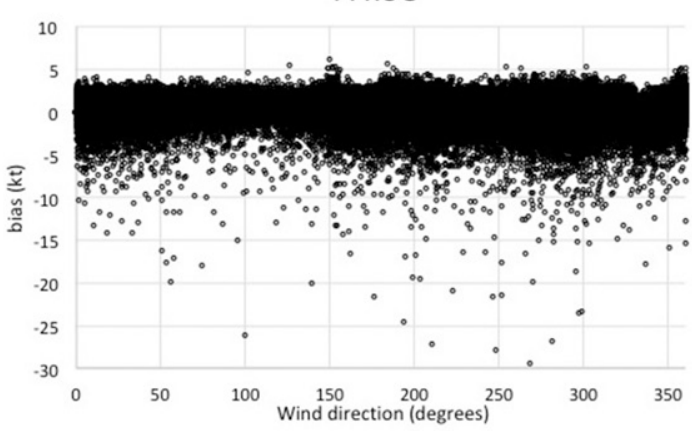

CLIM
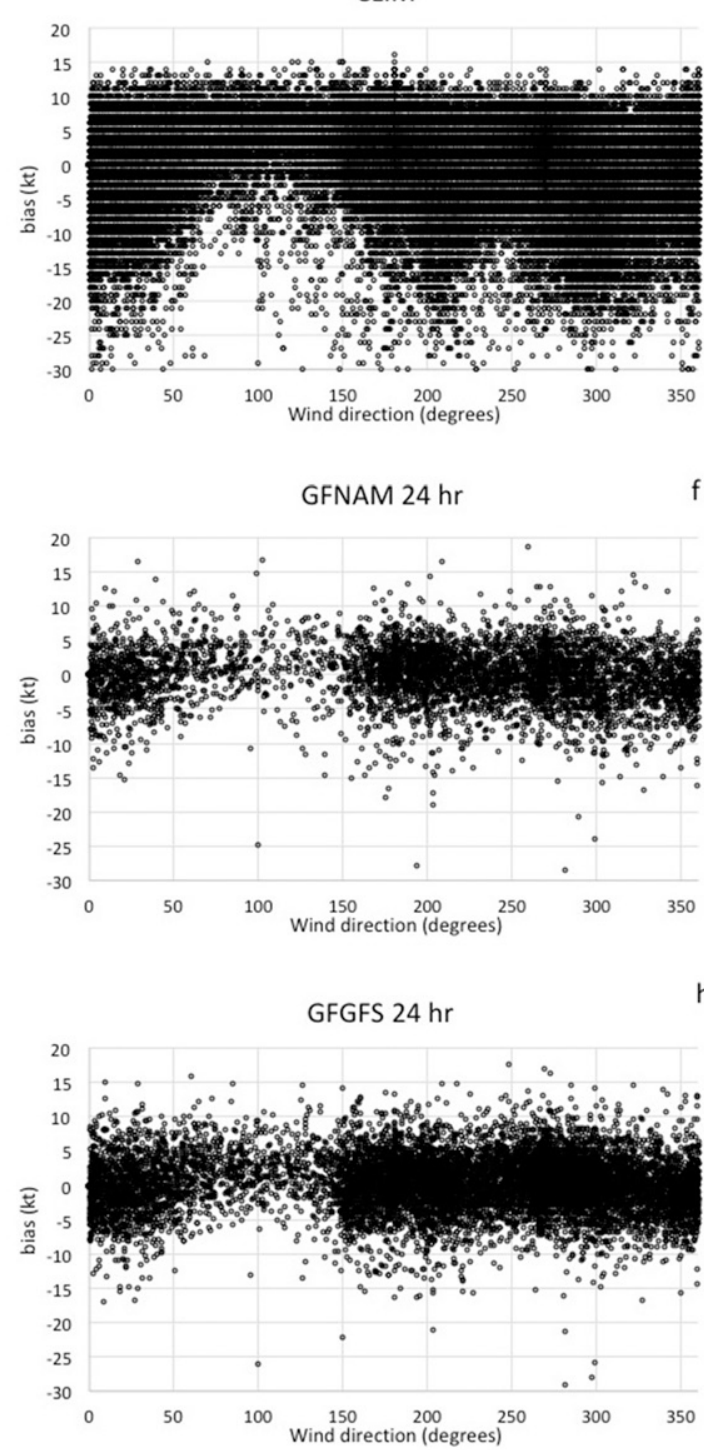

FIG. 6. Peak gust forecast bias at KPVD as a function of wind speed and wind direction. (a),(b) PPROG model; (c),(d) CLIM model; (e),(f) GFNAM model at $24 \mathrm{~h}$ forecast projection; and (g),(h) GFGFS model at 24-h forecast projection. 


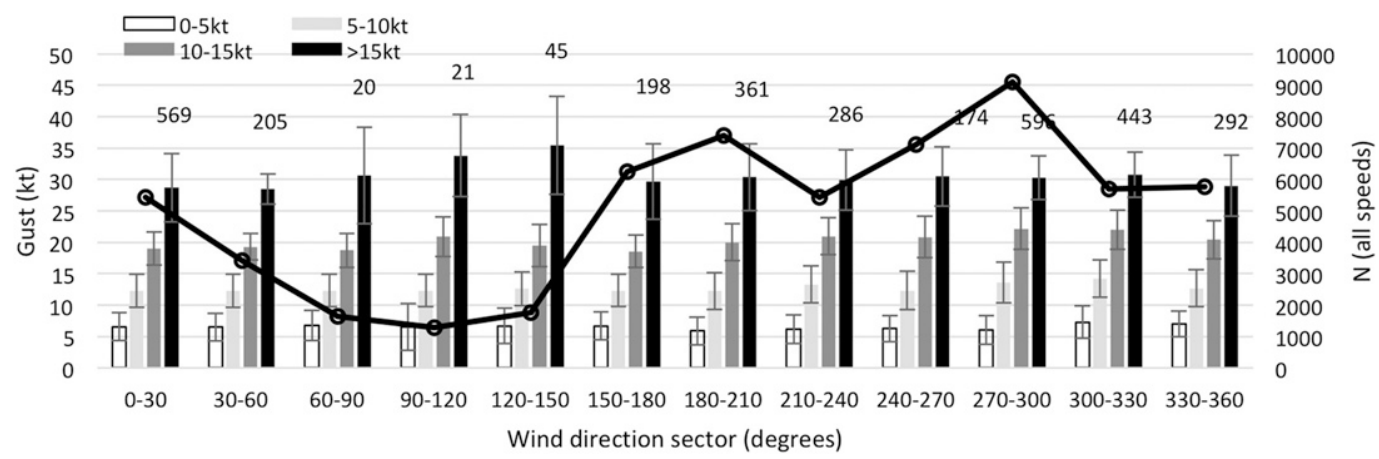

FIG. 7. Average peak gusts at KPVD as a function of mean wind speed and direction. Error bars indicate \pm 1 standard deviation. Also shown within each wind direction sector: the total number of observations (line; right axis) and number of observations with mean wind speed $>15 \mathrm{kt}$ (numbers above black bars).

more even during windy conditions, site characteristics and wind climatologies also play important roles. In this section we examine model performance at sites characterized by complex topography (KLND) and unusual wind climatology (KLAX).

Lander, Wyoming (KLND), at an elevation of $1704 \mathrm{~m}$, is located approximately $15 \mathrm{~km}$ to the northeast of the Wind River Range, a northwest-southeast-oriented range of the Rocky Mountains with a peak elevation of $4209 \mathrm{~m}$ MSL (Fig. 8a). Downslope winds from $180^{\circ}$ to $330^{\circ}$ are frequent, particularly within the $240^{\circ}-270^{\circ}$ sector (Fig. 8 b). Winds within the $180^{\circ}-330^{\circ}$ sector are particularly gusty, with gust factors exceeding 2.0 when sustained wind speeds are greater than $10 \mathrm{kt}$ (Fig. 8c). Peak wind gust forecasts at KLND using the no-skill CLIM model exhibit a strong directional dependence (Fig. 9a), with the largest errors corresponding to the downslope wind sector. Even the PPROG forecasts, prepared using observed rather than forecast wind speed and direction in conjunction with the meteorologically stratified gust factors, exhibit larger errors within this sector (Fig. 9b). These frequent and variable winds associated with the site topography are poorly predicted by the GFGFS (Fig. 9c) and GFNAM models (Table 3).

The KLAX ASOS site located at Los Angeles International Airport, $4 \mathrm{~km}$ from the coast of the Pacific

TABLE 3. Mean absolute errors in gust forecasts at all sites. Bold entries indicate skill [i.e., statistically significant (99\% confidence level) improvement over climatology]. LFP is the longest forecast projection (h) for which model forecasts at all projections $\leq$ LFP show skill. Models and data subsets are as described in Table 2.

\begin{tabular}{|c|c|c|c|c|c|c|c|c|c|c|}
\hline \multirow[b]{4}{*}{ Site } & \multirow{3}{*}{\multicolumn{2}{|c|}{$\begin{array}{l}\text { No-skill model } \\
\text { errors }(\mathrm{kt})\end{array}$}} & \multicolumn{4}{|c|}{$\begin{array}{l}\text { 24-h forecast projection peak gust forecast } \\
\text { error }(\mathrm{kt})\end{array}$} & \multicolumn{4}{|c|}{ Longest forecast projection (LFP) (h) } \\
\hline & & & \multicolumn{2}{|c|}{ GFNAM } & \multicolumn{2}{|c|}{ GFGFS } & \multicolumn{2}{|c|}{ GFNAM } & \multicolumn{2}{|c|}{ GFGFS } \\
\hline & & & \multicolumn{2}{|c|}{ Data subset } & \multicolumn{2}{|c|}{ Data subset } & \multicolumn{2}{|c|}{ Data subset } & \multicolumn{2}{|c|}{ Data subset } \\
\hline & PPROG & CLIM & NAM-ALL & NAM-19 & GFS-ALL & GFS-19 & NAM-ALL & NAM-19 & GFS-ALL & GFS-19 \\
\hline KGFK & 1.4 & 5.5 & 3.3 & 4.3 & 3.4 & 4.3 & 72 & 48 & 72 & 60 \\
\hline KSFF & 1.4 & 4.0 & 3.3 & 5.7 & 3.3 & 5.7 & 72 & - & 72 & - \\
\hline KSLE & 1.5 & 4.2 & 3.0 & 4.8 & 3.4 & 7.0 & 72 & - & 72 & - \\
\hline KMSN & 1.5 & 4.6 & 3.3 & 5.0 & 3.2 & 4.5 & 72 & 9 & 72 & 27 \\
\hline KBUF & 1.3 & 5.5 & 3.4 & 4.3 & 3.3 & 4.5 & 72 & 66 & 72 & 72 \\
\hline KLND & 2.0 & 4.6 & 4.8 & 9.0 & 4.9 & 8.7 & - & - & - & - \\
\hline KPVD & 1.3 & 4.8 & 3.2 & 5.2 & 3.3 & 4.4 & 72 & 21 & 72 & 39 \\
\hline $\mathrm{KCNK}$ & 1.5 & 5.8 & 3.7 & 4.7 & 3.7 & 4.4 & 72 & 66 & 72 & 72 \\
\hline $\mathrm{KMDH}$ & 1.5 & 4.8 & 3.4 & 6.0 & 3.3 & 5.1 & 72 & 9 & 72 & 9 \\
\hline $\mathrm{KCDC}$ & 1.6 & 5.1 & 3.7 & 5.3 & 3.8 & 5.2 & 72 & - & 72 & - \\
\hline KLAX & 1.4 & 2.5 & 2.9 & 3.4 & 2.8 & 4.2 & - & - & - & - \\
\hline KATL & 1.5 & 4.1 & 2.9 & 5.2 & 3.0 & 4.6 & 72 & 6 & 72 & - \\
\hline KROW & 1.8 & 4.7 & 3.8 & 5.5 & 4.7 & 6.8 & 45 & - & 21 & - \\
\hline KLFT & 1.3 & 4.0 & 3.3 & 5.7 & 3.3 & 4.6 & 57 & - & 72 & - \\
\hline KEYW & 1.1 & 4.3 & 3.4 & 4.5 & 3.1 & 3.8 & 72 & 9 & 72 & 66 \\
\hline
\end{tabular}



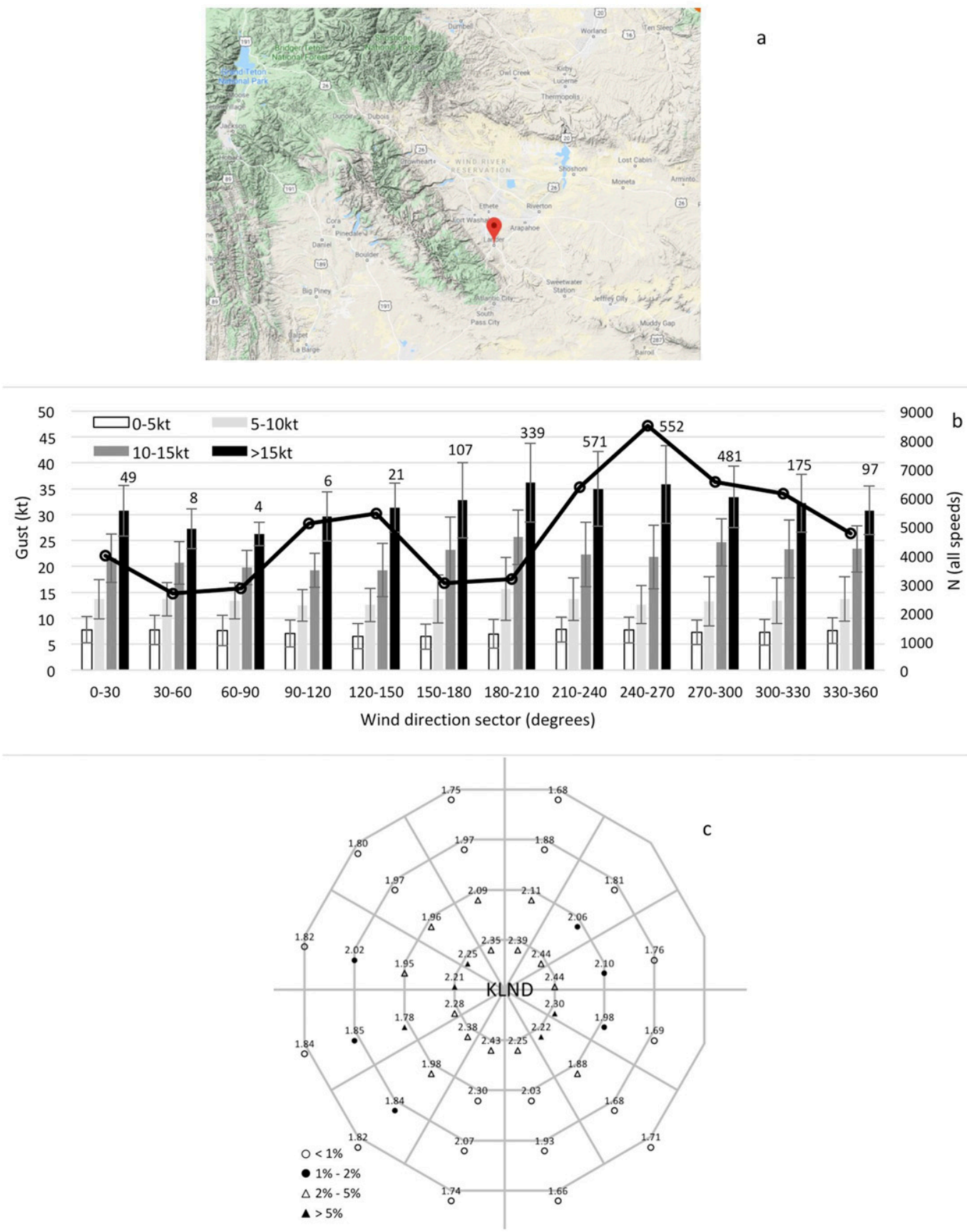

FIG. 8. (a) Location of KLND. (b) Average peak gusts at KLND as a function of mean wind speed and direction. Error bars indicate \pm 1 standard deviation. Also shown within each wind direction sector: the total number of observations (line; right axis) and number of observations with mean wind speed $>15 \mathrm{kt}$ (numbers above black bars). (c) Gust web showing meteorologically stratified gust factors at KLND based on 58536 hourly wind speeds, wind directions, and peak gusts during 2010-17. The concentric rings represent mean wind speed ranges: 0-5 (center), 5-10, 10-15, and $>15 \mathrm{kt}$ (outermost). The radial lines represent the boundaries of $30^{\circ}$ wind sectors, clockwise from north as per meteorological convention. The symbols represent the occurrence frequencies of mean wind speed and direction combinations. 


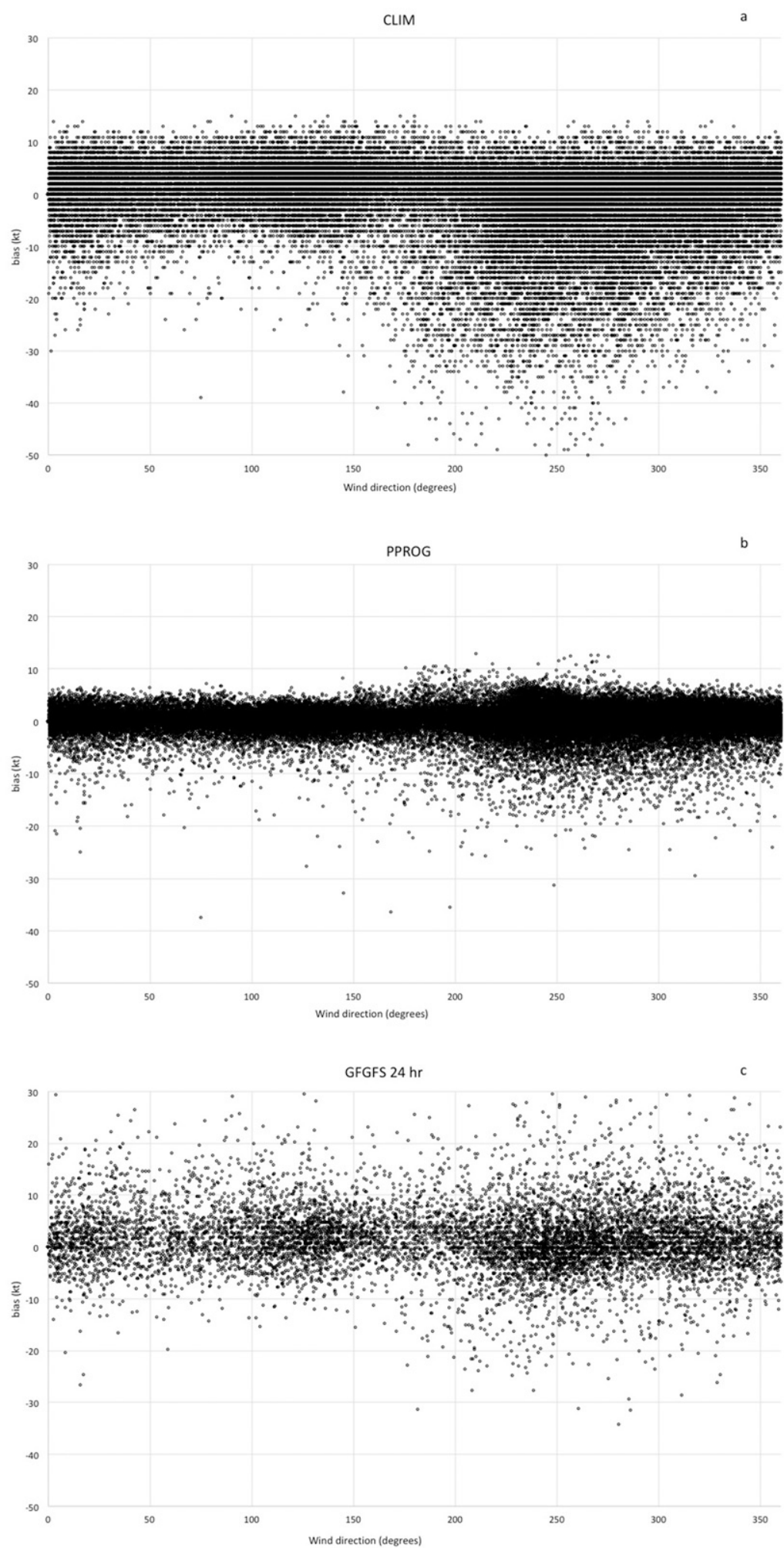

FIG. 9. Gust forecast bias at KLND as a function of observed wind direction. (a) CLIM forecasts, (b) PPROG forecasts, and (c) GFGFS 24-h projection forecasts. 

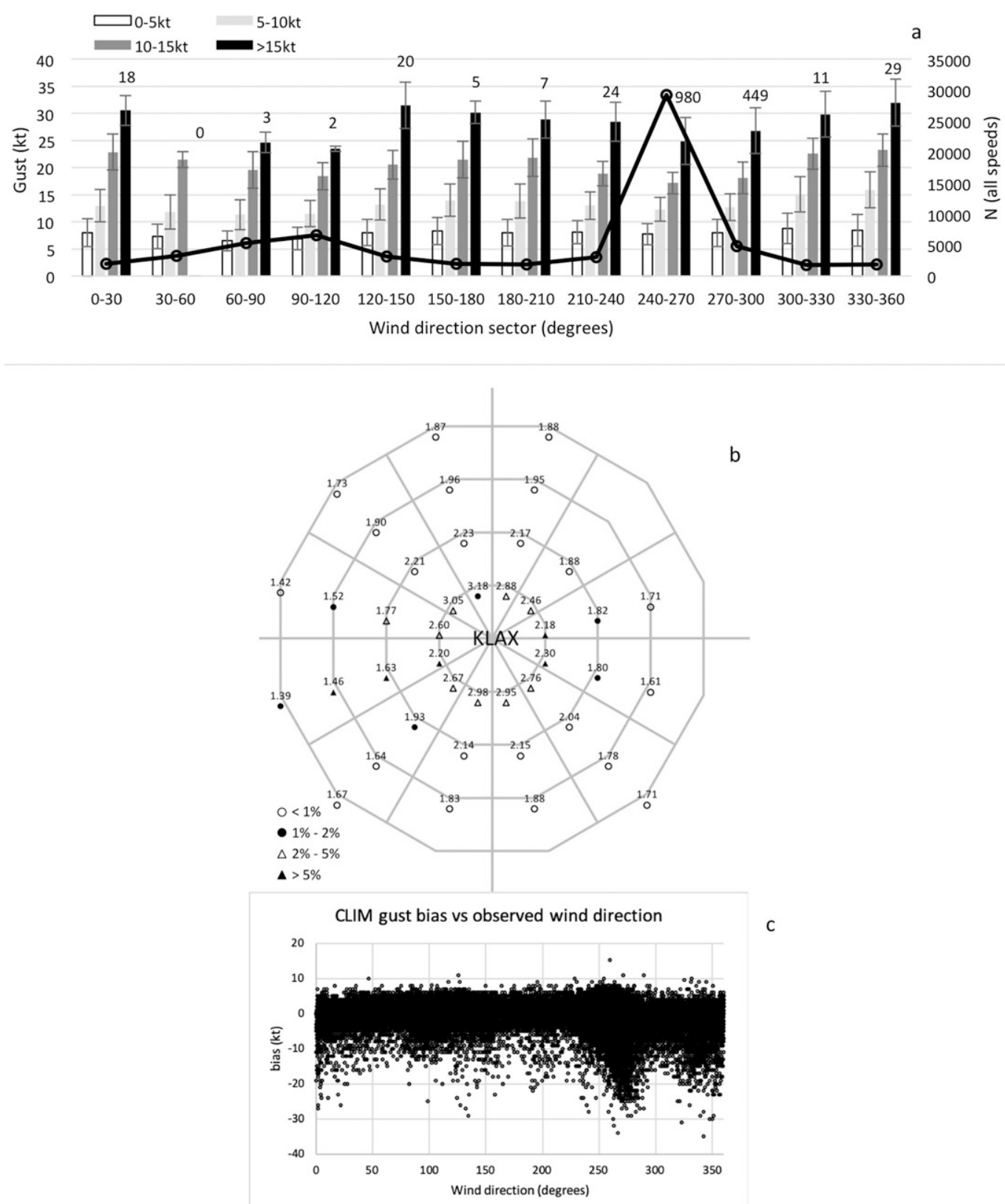

FIG. 10. (a) Average peak gusts at KLAX as a function of mean wind speed and direction. Error bars indicate \pm 1 standard deviation. Also shown within each wind direction sector: the total number of observations (line; right axis) and number of observations with mean wind speed $>15 \mathrm{kt}$ (numbers above black bars). (b) Gust web showing meteorologically stratified gust factors at KLAX based on 64904 hourly wind speeds, wind directions, and peak gusts during 2010-17. The concentric rings represent mean wind speed ranges: $0-5$ (center), 5-10, 10-15, and $>15 \mathrm{kt}$ (outermost). The radial lines represent the boundaries of $30^{\circ}$ wind sectors, clockwise from north as per meteorological convention. The symbols represent the occurrence frequencies of mean wind speed and direction combinations. (c) CLIM gust forecast bias at KLAX as a function of observed wind direction.

Ocean (Fig. 1) illustrates the influence of smooth, upwind topography. The wind climatology at this site is unusual relative to the other sites analyzed, with onshore winds from the $240^{\circ}-270^{\circ}$ sector occurring $45 \%$ of the time (Fig. 10a). Winds in this sector tend to be steady rather than gusty, with gust factors under 1.5 when sustained winds are greater than $10 \mathrm{kt}$ (Fig. 10b). This combination of frequent, nongusty onshore winds reduces the 
errors of no-skill CLIM forecasts (Fig. 10c), thus rendering the GFNAM and GFGFS peak gust forecasts less skillful than climatology (Table 3).

\section{Discussion and conclusions}

The meteorologically stratified gust factor (MSGF) model described by Harris and Kahl (2017) was evaluated at 15 locations across the United States during the period 2010-17. In this model peak wind gusts are estimated by coupling gust factors, site-specific climatological measure of "gustiness," with wind speed and direction forecasts. Gust factors were determined using 1-min resolution wind data to avoid averaging and reporting artifacts present in the ASOS hourly observations. Wind speed and direction forecasts were provided by NAM MOS and GFS MOS guidance at forecast projections ranging from 1 to $72 \mathrm{~h}$.

Mean absolute errors (MAEs) for "perfect prog" forecasts ranged from 1.1 to $2.0 \mathrm{kt}$ at the different locations analyzed, confirming the potential utility of the MSGF model provided that accurate wind speed and direction forecasts are available. MAEs for climatology forecasts, the benchmark against which model skill is assessed, ranged from 2.5 to $5.8 \mathrm{kt}$.

At 11 of the 15 sites analyzed, the MSGF model showed skill in predicting peak gusts out to projections of $72 \mathrm{~h}$ when coupled with GFS MOS and NAM MOS wind forecasts. This has important implications for operational forecasting, because the method can be utilized, or can supplement other gust prediction approaches, at any location for which the meteorologically stratified gust factors have been determined.

When the analysis was restricted to windy conditions (observed wind speed of at least $19 \mathrm{kt}$ ) the MSGF model exhibited skill in predicting peak gusts at forecast projections ranging from 6 to $72 \mathrm{~h}$ at roughly half of the sites analyzed. This somewhat less skillful gust factor model performance likely reflects reduced accuracy in wind forecasts during the windiest conditions. Peak gust forecasts at 6-, 12-, 18-, and 24-h projections showed skill at nearly all sites analyzed, and at roughly half of the sites when the analysis was restricted to windy conditions.

At most sites the MSGF model performed better when coupled with GFS MOS rather than NAM MOS wind forecasts. With developments in MOS methodologies (Pelosi et al. 2017), however, new products may emerge that provide superior wind guidance to couple with the gust factor model.

Site characteristics (horizontal inhomogeneities in surface roughness) and local peculiarities in wind climatologies were also shown to exert impacts on gust factor model performance. At sites with heterogeneous terrain for which accurate wind forecasting is challenging, climatology may serve as a useful substitute in forecasting peak gusts.

Despite its importance in weather forecasting, reliable gust prediction has remained elusive. The meteorologically stratified gust factor method represents a viable option for the operational prediction of peak wind gusts, although model performance will be sensitive to the quality of the necessary wind speed and direction forecasts, as demonstrated here using NAM MOS and GFS MOS guidance. At some sites a combination of the MSGF model and climatology forecasts may provide a means for forecasting peak wind gusts over a variety of meteorological conditions.

The gust web diagrams and peak gust climatologies included in the supplemental material provide the means to apply the model at the 15 sites analyzed here. Future efforts will include determining meteorologically stratified gust factors at additional ASOS sites, and on assessing model performance during specific types of gust-producing weather phenomena.

Acknowledgments. The author is grateful to Austin Harris at UW-Milwaukee and the anonymous referees for numerous helpful comments and suggestions.

\section{REFERENCES}

Adame, J. A., L. Lope, P. J. Hidalgo, M. Sorribas, I. GutiérrezÁlvarez, A. del Águila, A. Saiz-Lopez, and M. Yela, 2018: Study of the exceptional meteorological conditions, trace gases and particulate matter measured during the 2017 forest fire in Doñana Natural Park, Spain. Sci. Total Environ., 645 , 710-720, https://doi.org/10.1016/j.scitotenv.2018.07.181.

Ashley, W. S., and A. W. Black, 2008: Fatalities associated with nonconvective high-wind events in the United States. J. Appl. Meteor. Climatol., 47, 717-725, https://doi.org/10.1175/ 2007JAMC1689.1.

EPA, 2015: AERMINUTE user's guide. EPA-454/B-15-006, 65 pp., https:/www3.epa.gov/ttn/scram/7thconf/aermod/aerminute_ userguide.pdf.

Fovell, R. G., and Y. Cao, 2014: Wind and gust forecasting in complex terrain. 15th WRF Users' Workshop, Boulder, CO, NCAR, 5A.2, http://www2.mmm.ucar.edu/wrf/users/workshops/ WS2014/ppts/5A.2.pdf.

Ghirardelli, J. E., 2005: An overview of the redeveloped Localized Aviation MOS Program (LAMP) for short-range forecasting. 21st Conf. on Weather Analysis and Forecasting/17th Conf. on Numerical Weather Prediction, Washington, DC, Amer. Meteor. Soc., 13B.5, http://ams.confex.com/ams/pdfpapers/95038.pdf.

_ , and B. Glahn, 2010: The Meteorological Development Laboratory's aviation weather prediction system. Wea. Forecasting, 25, 1027-1051, https://doi.org/10.1175/2010WAF2222312.1.

Glahn, H. R., and D. A. Lowry, 1972: The use of model output statistics (MOS) in objective weather forecasting. J. Appl. Meteor., 11, 1203-1211, https://doi.org/10.1175/1520-0450(1972) 011<1203:TUOMOS>2.0.CO;2. 
Gutiérrez, A., and R. G. Fovell, 2018: A new gust parameterization for weather prediction models. J. Wind Eng. Ind. Aerodyn., 177, 45-59, https://doi.org/10.1016/j.jweia.2018.04.005.

Harris, A. R., and J. D. W. Kahl, 2017: Gust factors: Meteorologically stratified climatology, data artifacts, and utility in forecasting peak gusts. J. Appl. Meteor. Climatol., 56, 3151-3166, https:// doi.org/10.1175/JAMC-D-17-0133.1.

Jung, C., D. Schindler, A. Buchholz, and J. Laible, 2017: Global gust climate evaluation and its influence on wind turbines. Energies, 10, 1474, https://doi.org/10.3390/en10101474.

Klawa, M., and U. Ulbrich, 2003: A model for the estimation of storm losses and the identification of severe winter storms in Germany. Nat. Hazards Earth Syst. Sci., 3, 725-732, https:// doi.org/10.5194/nhess-3-725-2003.

Letson, F., S. C. Pryor, R. J. Barthelmie, and W. Hu, 2018: Observed gust wind speeds in the coterminous United States, and their relationship to local and regional drivers. J. Wind Eng. Ind. Aerodyn., 173, 199-209, https://doi.org/10.1016/ j.jweia.2017.12.008.

Ma, C. G., T. J. Wang, Z. L. Zang, and Z. J. Li, 2018: Comparisons of three-dimensional variational data assimilation and model output statistics in improving atmospheric chemistry forecasts. Adv. Atmos. Sci., 35, 813-825, https://doi.org/10.1007/s00376017-7179-y.

Manasseh, R., and J. H. Middleton, 1999: The surface wind gust regime and aircraft operations at Sydney Airport. J. Wind Eng. Ind. Aerodyn., 79, 269-288, https://doi.org/10.1016/S01676105(97)00293-6.

Mendenhall, W., D. D. Wackerly, and R. L. Schaeffer, 1990: Mathematical Statistics with Applications. 4th ed. PWS-Kent Publishing, $818 \mathrm{pp}$.

Pelosi, A., H. Medina, J. Ven Den Bergh, S. Vannitsem, and G. B. Chirico, 2017: Adaptive Kalman filtering for postprocessing ensemble numerical weather predictions. Mon. Wea. Rev. 145, 4837-4854, https://doi.org/10.1175/MWR-D-17-0084.1.

Pryor, S. C., R. Conrick, C. Miller, J. Tytell, and R. J. Barthelmie, 2014: Intense and extreme wind speeds observed by anemometer and seismic networks: An eastern U.S. case study.
J. Appl. Meteor. Climatol., 53, 2417-2429, https://doi.org/ 10.1175/JAMC-D-14-0091.1.

Sheridan, P., 2011: Review of techniques and research for gust forecasting and parameterisation. UKMO Forecasting Research Tech. Rep. 570, 19 pp.

_ 2018: Current gust forecasting techniques, developments and challenges. Adv. Sci. Res., 15, 159-172, https://doi.org/10.5194/ asr-15-159-2018.

Sinden, G., 2007: Characteristics of the UK wind resource: Long term patterns and relationship to electricity demand. Energy Policy, 35, 112-127, https://doi.org/10.1016/j.enpol.2005.10.003.

Struzewska, J., J. W. Kaminski, and M. Jefimow, 2016: Application of model output statistics to the GEM-AQ high resolution air quality forecast. Atmos. Res., 181, 186-199, https://doi.org/ 10.1016/j.atmosres.2016.06.012.

Suomi, I., and T. Vihma, 2018: Wind gust measurement techniques-From traditional anemometry to new possibilities. Sensors, 18, 1300, https://doi.org/10.3390/s18041300.

,$- \ldots$, S.-E. Gryning, and C. Fortelius, 2013: Wind gust parameterizations at heights relevant for wind energy: A study based on mast observations. Quart. J. Roy. Meteor. Soc., 139, 1298-1310, https://doi.org/10.1002/qj.2039.

Thorarinsdottir, T. L., and T. Gneiting, 2010: Probabilistic forecasts of wind speed: Ensemble model output statistics by using heteroscedastic censored regression. J. Roy. Stat. Soc., 173A, 371-388, https://doi.org/10.1111/j.1467-985X.2009.00616.x.

Usbeck, T., T. Wohlgemuch, C. Pfister, R. Volz, M. Beniston, and M. Dobbertin, 2009: Wind speed measurements and forest damage in Canton Zurich (central Europe) from 1891 to winter 2007. Int. J. Climatol., 30, 347-358, https://doi.org/ 10.1002/joc.1895.

Van Den Bossche, N., M. A. Lacasse, and A. Janssens, 2013: A uniform methodology to establish test parameters for watertightness testing. Build. Environ., 63, 145-156, https://doi.org/ 10.1016/j.buildenv.2012.12.003.

Veenhuis, B. A., 2013: Spread calibration of ensemble MOS forecasts. Mon. Wea. Rev., 141, 2467-2482, https://doi.org/10.1175/ MWR-D-12-00191.1. 